\title{
A Calorimetric Study of Ti-6Al-4V Alloy
}

\author{
S. Manikandan ${ }^{1 *}$, S. Ramanathan ${ }^{2}$ and V. Ramakrishnan ${ }^{3}$ \\ 'Department of Mechanical Engineering, Annamalai University, India; manikandan74@gmail.com \\ ²Department of Manufacturing Engineering, Annamalai University, India \\ ${ }^{3}$ Thermal Systems Group, ISRO Satellite Centre, Bangalore, India; vramki@isac.gov.in
}

\begin{abstract}
Ti-6Al-4V titanium alloy is widely used in industrial applications such as aeronautic and aerospace due to its good mechanical properties at high temperatures. The aim of the work is to determine the heat capacity of the thermal cycled titanium alloy. The cylindrical specimens of dimension $3 \pm 0.1 \mathrm{~mm}$ in diameter and $2.5 \pm 0.1 \mathrm{~mm}$ in length were machined from the CNC machine. The specimens were subject to two different types of heat treatments (Solution treated and annealed). First type of heat treatment (annealing) is processed by heating the specimen to a temperature of $750^{\circ} \mathrm{C}$ for 4 hours and it is cooled in the furnace to reach the atmospheric temperature. Second type of heat treatment (solution treating) is processed by the specimen is heated to a temperature of $975^{\circ} \mathrm{C}$ for 1 hour and it is quenched in a solution containing water with $5 \%$ of caustic soda. After quenching (delay of 6 second), aging was done at $450^{\circ} \mathrm{C}$ for 4 hours and then it is furnace cooled to reach atmospheric temperature The heat treated specimens were thermal cycled in a specially designed thermal cycling apparatus for different cycles Heat flow and the flow of energy into or out of the sample as a function of temperature was measured by using Differential Scanning Calorimetry (DSC). The heat flow response is recorded as a function of actual sample temperature range from $-120^{\circ} \mathrm{C}$ to $380^{\circ} \mathrm{C}$. The measurements of the heat capacity by DSC with an accuracy of $\pm 2 \%$ have been reported. This study restrict the use of DSC as a truly quantitative calorimetric technique and concentrates mainly on the practical set of experimental heat capacity data measured over a temperature range for different aerospace materials being used/developed indigenously for the Indian Space Programme.
\end{abstract}

Keywords: Thermal Analysis, Differential Scanning Calorimeter, Specific Heat, Heat Treatment.

\section{Introduction}

Ti-6Al-4V materials are used for aerospace applications, because of the high strength-to-weight ratio, enhanced mechanical and thermal properties over conventional materials. Tailored made properties make them attractive in a variety of applications. This study restricts the use of DSC as a truly quantitative calorimetric technique and concentrates mainly on the practical set of experimental heat capacity data measured over a temperature range for different thermal cycled Ti-6Al-4V materials. Calorimetric is an analysis technique, which is a part of thermal analysis methods. In its broadest sense, thermal analysis refers to the measurement of changes in properties of sub- stances under a controlled temperature program. The most commonly used temperature programs are either isothermal hold or heating at constant rate. Apart from the more common applications, calorimetry has been applied extensively to the analysis of light metals: especially Titanium based alloys [1]. The performance of the 'Thermal Control System' (TCS) totally depends upon the thermal behaviour of the materials used in its elements. The measurements of the thermal properties of materials are fundamental for better understanding of the thermal design. The external heat load variation to the spacecraft causes a rise in temperature, which is inversely proportional to the thermal capacity. In spacecrafts, higher thermal capacity will cause a lower temperature swing during an orbit. Historically, specific heat

\footnotetext{
* Corresponding author:

S. Manikandan (manikandan74@gmail.com)
} 
capacity has been measured at room temperature and is assumed to be invariant with temperature. But, the heat capacity of solid materials increases steadily with rise in temperature and decreases rapidly with decreasing temperatures [2]. Experimentally, the specific heat capacity is often derived from measurements of the rates of heat input and temperature rise of the specimen (or) from the measurements of the changes in enthalpy (or heat content) of the specimen with changing temperature. The calorimetric techniques are best suited for the experimental determination of specific heat capacities. The thermal technique Differential Scanning Calorimetry (DSC) is applicable for the measurement of specific heat capacity of chemically stable, non-volatile, condensed phases, solids, pastes, powders and nonvolatile liquids with an accuracy of $\pm 2 \%$ or less. Measurement of heat capacity $(\mathrm{Cp})$ has generally been regarded as the ultimate test for characterizing a material, as it is a bulk property that gives more information for thermodynamic studies [5]. Calorimetry has been applied extensively to the analysis of light metals, especially Titanium based alloys.

Thermal cycling is a temperature modulation process developed to improve the performance, strength and longevity of a variety of materials [3]. Probably best described as 'advanced cryogenics', thermal cycling has been applied chiefly to metals to-date; It is currently used by a number of industries where enhanced material performance is desired. During the thermal cycling process, materials are alternately cooled and heated until they experience molecular reorganization. This reorganization 'tightens' or optimizes the particulate structure of the material throughout, relieving stresses, and making the metal denser and more uniform (thereby minimizing flaws or imperfections). The tighter structure also enhances the energy conductivity and heat distribution characteristics of the material [4]. Thermal Cycling minimizes 'hotspots', enhances cooling, and impedes the ability and tendency of metals to vibrate. Significantly reducing vibration as a factor in metal fatigue slows down the metal's eventual failure or breakage. Corrosion resistance is enhanced as a result of molecular uniformity because the metal's ability to impede oxidation and chemical degradation is strengthened.

\section{Experimental Study}

The cylindrical specimens of dimension $3 \pm 0.1 \mathrm{~mm}$ in diameter and $2.5 \pm 0.1 \mathrm{~mm}$ in length were machined from the CNC machine. The specimens were subject to two different types of heat treatments (Solution treated and annealed).The heat treated specimens were thermal cycled in a specially designed thermal cycling apparatus as shown in Figure 1. The basic thermal cycling apparatus comprises a muffle furnace, forced air cooling unit, electronic experimental controls unit and timer unit. The timer unit controls the heating and cooling time period of the cyclic process and regulates the flow of compressed air to the pneumatic cylinder through the electrically operated pneumatic valve. Further the experimental set-up consist of pneumatic components like double acting reciprocating air compressor, air control main valve, air filter, air regulator, air lubricator, electrically operated pneumatic valve and pneumatic cylinder. The pneumatic cylinder piston carries the cage, in which the test sample is placed. The cage is made up of stainless steel with three compartments to carry similar test samples in it. The timer unit counts the number of cycles and stops the process after completing the required number of cycles. Manual handling and monitoring of the sample during the thermal cycling process is minimized due to this automation. Pneumatic piston actuator was built to cycle the specimen in and out of the furnace. Where, the required temperature was maintained in the furnace. The thermal cycle imposed had dwell time of 2 minutes in and out of the furnace. Samples were cooled by forced air cooling at a pressure of 2 bars. Heat treated specimens were subjected to thermal cycling in the range of 500, 1000 and 1500 cycles.

The measurement of $\mathrm{Cp}$ has been carried out with a commercially available research grade Differential Scanning Calorimeter (DSC - Model Q 100, V2.1, TA Instruments, USA) whose operation is based on the thermal heat flow technique. This measurement involved three DSC scansbase line, standard reference and the test specimen. The first run was taken as the baseline. The second run was taken with the standard reference material (sapphire) in the cell. Then, the third run was taken with the sample in the cell. During these runs, the sapphire and the unknown sample are placed on the same place inside the DSC cell. The heating rate selected was $20^{\circ} \mathrm{C} / \mathrm{min}$ from $150^{\circ}$ to $400^{\circ} \mathrm{C}$. Nitrogen was used as a purge gas at the flow rate of 50.0 $\mathrm{ml} / \mathrm{min}$. To minimize the errors in measurements, all runs were carried out directly without using any crucible in the same instrument under identical heating conditions. There is an improvement of the temperature resolution due to the decrease in the response time of the apparatus. The masses of specimen were determined by weighing in an accurate digital single pan balance and maintained close to the mass 


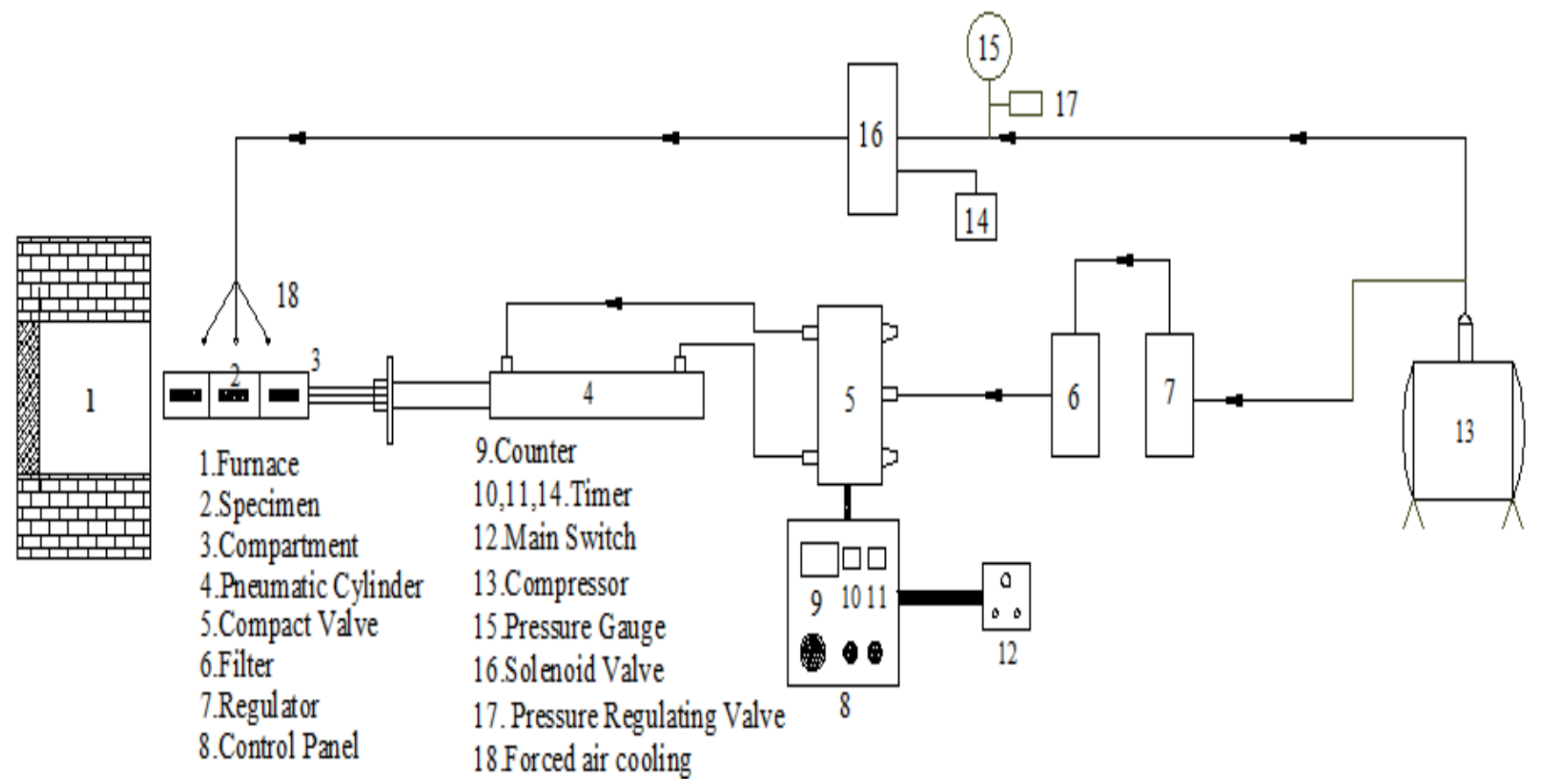

Figure 1. Thermal cycling apparatus.

of the standard reference material to obtain the required accuracy.

The DSC cell was calibrated before unknown sample measurements with high-purity SRM such as Tin and Indium procured with certified latent heats and melting points. Then, it is calibrated with standard synthetic sapphire procured from TA Instruments (USA), which is the reference material and scan for the heat flow calibration before the $\mathrm{Cp}$ measurements of samples [5]. The sapphire gives reliable, well-certified measurement data which are reproducible and reported [6]. The thermal change occurred in the sample material during the temperature range under consideration with reference to that of the standard reference material provides the base for the $\mathrm{Cp}$ measurement. The temperature difference between the standard reference material and the sample is directly proportional to the temperature difference between them. Based on the heat flow $(\mathrm{W} / \mathrm{g})$, total heat $(\mathrm{J} / \mathrm{g})$ at a particular temperature $\left({ }^{\circ} \mathrm{C}\right)$ point in the selected measurement range, the heat capacity $\left(\mathrm{J} / \mathrm{g} /{ }^{\circ} \mathrm{C}\right)$ was computed by the built in custom made Advantage $^{\mathrm{mw}}$ software. In all the cases, measurements were made with a minimum of two samples. The measurement on each sample was carried out at least thrice. Instead of preconditioning the samples in a separate furnace the first run carried out inside the cell, which helps to remove the process-induced residual stresses and the surface absorbed moisture. The second run carried out after cooling the sample to room temperature, without disturbing the experimental set-up, provided realistic values. In all cases, the measured values obtained in the second run were better and reliable. The systematic errors can be reduced by good up keeping and careful calibration of the system. Repeat measurements confirm the precision of the measurement data. The individual contributions of errors were worked out and the total measurement error in Cp measurement by DSC is restricted to $\pm 2 \%$ by adopting a well-laid systematic measurement approach [7].

\section{Results and Discussion}

The heat capacity measurements were carried out on each two samples of the thermal cycled titanium specimens. Measurements were carried out twice in all six samples Instead of preconditioning the samples in a separate furnace, the first run carried out inside the module which helps to remove the process-induced residual stresses and the surface absorbed moisture. The second run carried out, after cooling the sample to room temperature, without disturbing the experimental set-up, provided realistic values. The heating rate selected was $20^{\circ} \mathrm{C} / \mathrm{min}$ from $-150^{\circ} \mathrm{C}$ to 
$400^{\circ} \mathrm{C}$. Nitrogen was used as a purge gas at the flow rate of $50.0 \mathrm{ml} / \mathrm{min}$. The DSC traces of the heat capacity and total heat as a function of the temperature were plotted.

The heat capacity of thermal cycled titanium alloy was measured. The heat treatment and thermal cycling influence the resultant heat capacities of the alloy. The results of the heat capacity measurement are shown in Figures 2-6 as a function of temperature. Figures $2 \& 3$ shows the variation in the measured heat capacity between the 500, 1000 \& 1500 cycles.

From Figure 2, it is observed that the heat capacity of the samples increases with an increase in temperature. Specific heat capacity of the 1500 cycled specimen shows higher value when compared to $500 \& 1000$ cycles. Thermal cycling influences the specific heat capacity value at higher number of cycles and it is proved in the solution treated specimen also, which is shown in Figure 3. Solution treated specimens always shows the higher specific heat capacity value when compared to annealed specimen in all the three cycles $(500,1000 \& 15000)$ is shown in Figure 4-6. and this

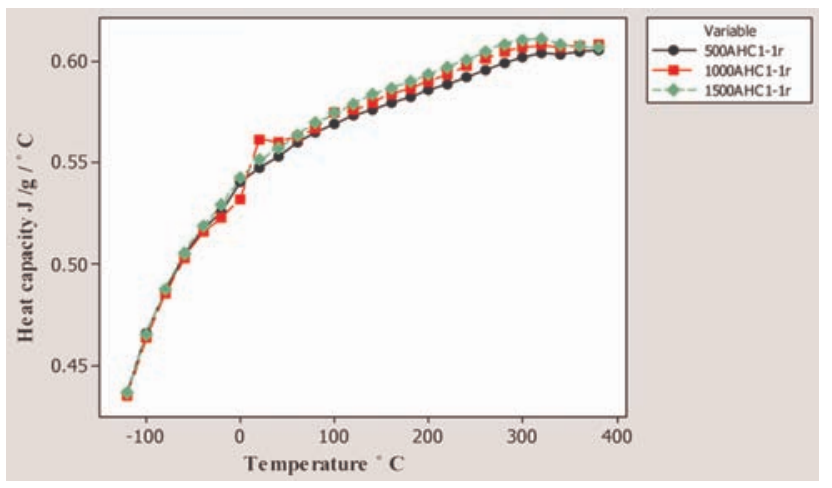

Figure 2. Heat capacity of different thermal cycled (500, 1000, 1500 cycles) annealed specimens (AHC).

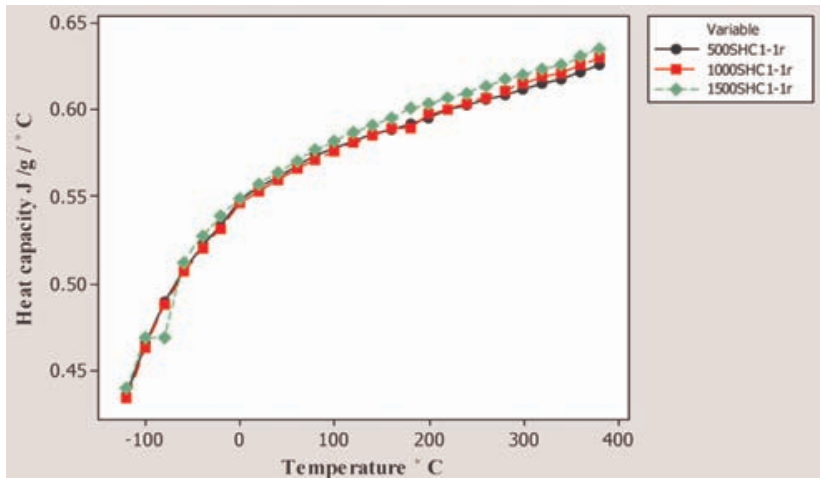

Figure 3. Heat capacity of different thermal cycled (500, 1000,1500 cycles) solution treated specimens (SHC). is because of heating the $\alpha-\beta$ alloy to the solution treating temperature produces a higher ratio of $\beta$ phase. This partitioning of phases is maintained by quenching and subsequent aging provides high strength. Both annealed and solution treated specimen shows higher value of specific heat capacity when compared to without thermal cycled specimens. A marginal variation of specific heat capacity value occurs after the temperature reaches $100{ }^{\circ} \mathrm{C}$ for the annealed and solution treated specimen is witnessed from Figures 4, 5, 6. At ultra low temperature there is no marginal change in the specific heat capacity value $\left(-120^{\circ} \mathrm{C}-60^{\circ} \mathrm{C}\right)$. Solution treated specimens exhibits a marginal rise when compared to annealed specimen at higher temperature. From $-40^{\circ} \mathrm{C}$ onwards the specific heat capacity value of solution treated specimens gets deviated from the annealed specimen. The specific heat capacity value of $0.5263 \mathrm{~J} / \mathrm{g} /{ }^{\circ} \mathrm{C}$ was obtained at $-40^{\circ} \mathrm{C}$ itself with the influence of thermal cycling. From Figure 2-6 it is observed that the heat capacity increase is not perfectly linear, and this can be attributed to an increase in the amplitude of vibration of the atoms of the constituents of the material with increase in temperature. Thermal cycling influences the heat capacity up to 1000 cycles.

The Heat capacity data for Ti-6Al-4V alloys, measured with the intermediate temperature does not show any abrupt changes in slope. Figure 2-6 shows the specific heat capacity in the temperature range of $-120^{\circ} \mathrm{C}$ to $380^{\circ} \mathrm{C}$. For all two heat treated specimens, the heat capacity increases monotonically in this temperature range. For solution treated specimens, the higher slope in the heat capacity above $100^{\circ} \mathrm{C}$ is probably due the heat absorbed during the dissolution of precipitates still remaining in the microstructure at these temperatures [8-10]. Brooks et al. have reported two polynomials covering data measured by adiabatic calorimetry. The present work extends the technique to industrial alloys. Since reliable literature data are not available for the Thermal cycled alloys, a thorough validation was not possible [11]. In the range where data were available for comparison. The slope computed from the polynomial, representing Brook et al's high temperature data is in good agreement with the slope above $300^{\circ} \mathrm{C}$ [12], of the current work. However, the polynomial does not extend into the range of high-temperature data of the current work. So, an extended comparison cannot be made. For Ti-6Al-4V, Cp data above $300{ }^{\circ} \mathrm{C}$ is in reasonably good agreement $(<13 \%$ average difference) with data measured by Cezairliyan et al. [13] using a similar system.

The second run shows the measured value trends are in similar patens. The variations in heat capacity of alloy are 


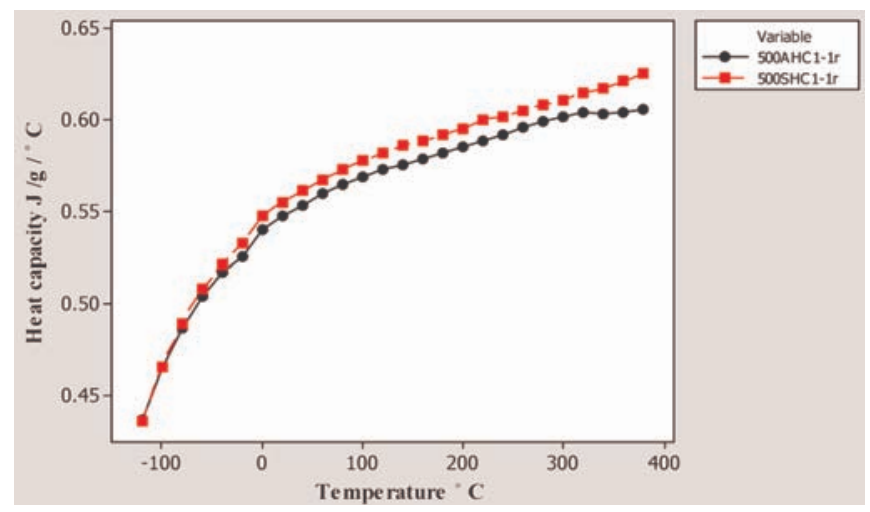

Figure 4. Heat capacity of 500 thermal cycled annealed \& solution treated specimens.

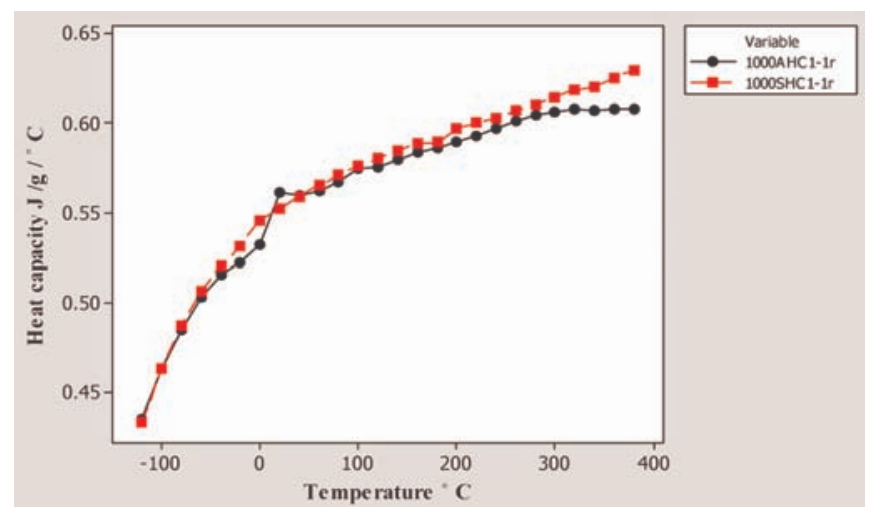

Figure 5. Heat capacity of 1000 thermal cycled annealed \& solution treated specimens.

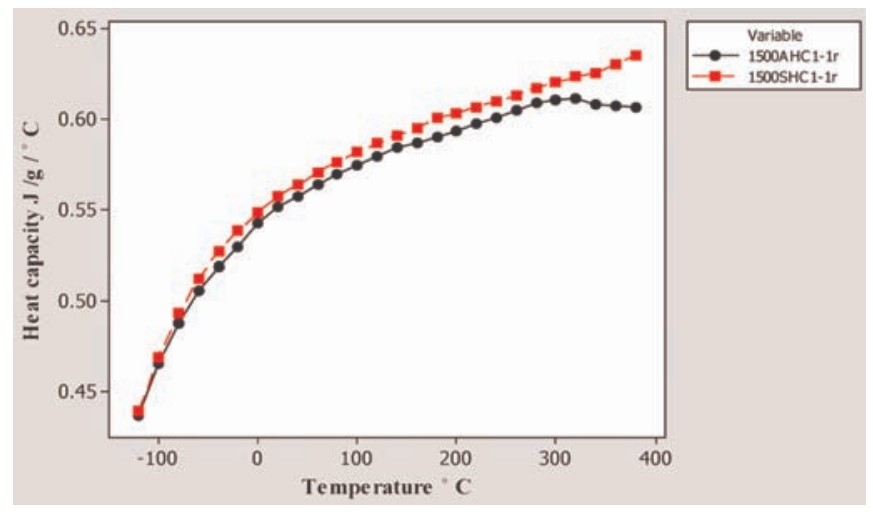

Figure 6. Heat capacity of 1500 thermal cycled annealed \& solution treated specimens.

due to thermal cycling. The heat capacity measurement of two heat treated alloy shows, similar patens of exothermic and endothermic peaks at same temperature values. From Figures 7-9, it is observed that the total heat calculated is linearly increases with increase in temperature. Further, the

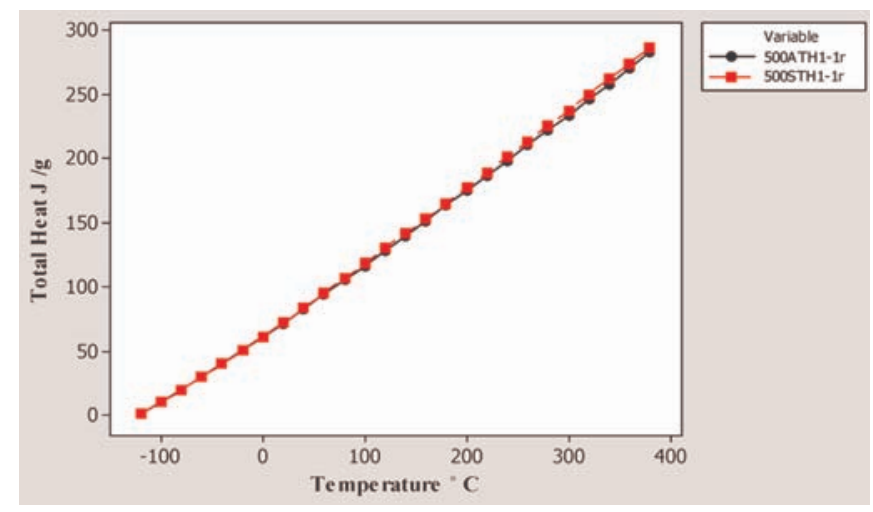

Figure 7. Total heat of 500 thermal cycled annealed \& solution treated specimens.

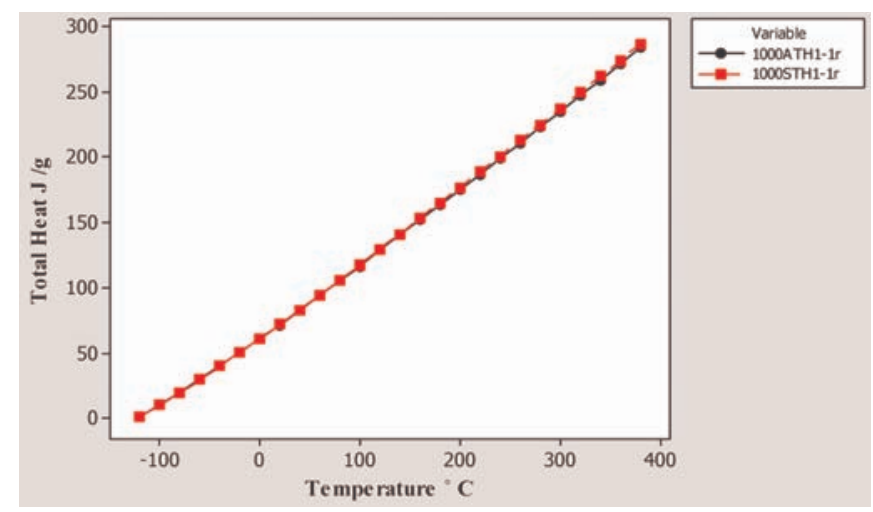

Figure 8. Total heat of 1000 thermal cycled annealed \& solution treated specimens.

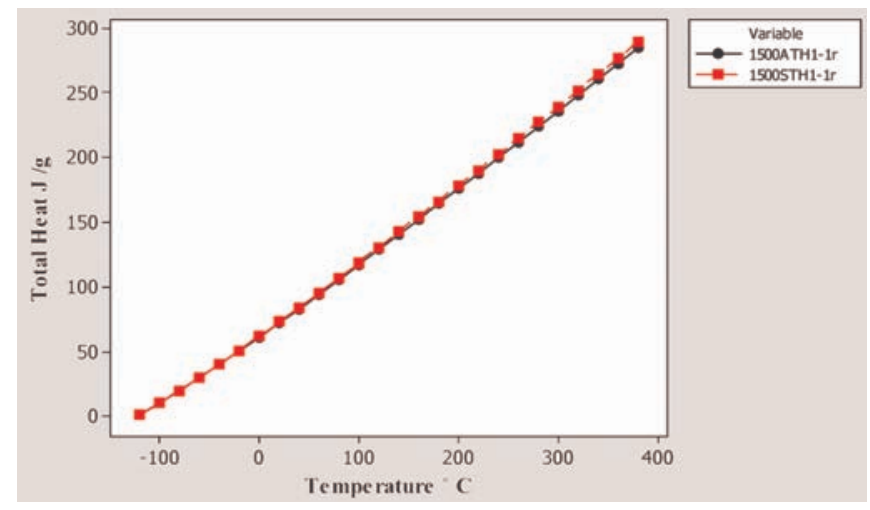

Figure 9. Total heat of 1500 thermal cycled annealed \& solution treated specimens.

linear reduction of total heat is observed Data generated from these experiments fill the void for the thermo physical properties of heat treated and thermal cycled titanium alloys in temperature ranges $\left(-120^{\circ} \mathrm{C}\right.$ to $\left.380^{\circ} \mathrm{C}\right)$. From the interpretation of thermo physical property data measured 
by this techniques shows the heat treatment history, phase stability, are well understood

Influence of heat treatment and thermal cycling on the specific heat capacity of Titanium (Ti-6Al-4V) alloy were investigated.

\section{Conclusions}

Heat capacity of heat treated (Solution treated and annealed) and thermal cycled (500, 1000, 1500 cycles) Titanium (Ti-6Al-4V) alloy specimens were analyzed at ultra-low temperature $\left(-120^{\circ} \mathrm{C}\right)$ to $380^{\circ} \mathrm{C}$. Heat capacity study from the samples has led to the following inferences.

1. The heat capacity of both solutions treated and annealed specimens increases with an increase in temperature.

2. Thermal cycling influences the increase of heat capacity in both solutions treated and annealed specimens.

3. Solution treated specimen shows higher value when compared to annealed specimen.

4. Solution treated and annealed specimens has higher heat capacity value when compared to without heat treated specimen.

5. Solution treated specimen shows higher value after $300^{\circ} \mathrm{C}$ for all the three cycles.

6. At ultra low temperature there is no marginal change in the specific heat capacity values $\left(-120^{\circ} \mathrm{C}-60^{\circ} \mathrm{C}\right)$

7. From $-40^{\circ} \mathrm{C}$ onwards the specific heat capacity value of solution treated specimens gets deviated from the specific heat capacity value of annealed specimen.

8. There is no marginal difference in total heat for Solution treated and annealed specimens in all the three cycles.

9. The average absolute deviation in specific heat capacity is about $10 \%$ for annealed specimen. The average absolute deviation is about $12 \%$ for solution treated specimen.

\section{Acknowledgements}

The authors are thankful to Mr. D. Raghavendra Kumar and Mr. V. Ramakrishnan, ISRO Satellite Centre, Bangalore for their assistance in experimental works.

\section{References}

1. Gilmore D G (2002). spacecraft thermal control hand book, Aerospace Press, California. Fundamental Technologies, vol $1,21-71$.

2. Lam T T, ed. (1998). Study of advanced satellite thermal management technology, Aerospace Corporation, TOR98(1057)-2.

3. Geng H and He S (1997). Thermal cycling behavior of As-Quenched and aged Ti-6Al-4V alloy, Metallurgical and Material Transactions A, vol 28(9), 1809-1814.

4. ASM International (1994). Material Properties Handbook: Titanium Alloys.

5. Karthikeyan B, Ramanathan S et al. (2010). A calorimetric study of $7075 \mathrm{Al} / \mathrm{SiCp}$ composites. International Journal of Materials and Design, vol 31(supplement 1), S92-S95.

6. Ramakrishnan V, Ramasamy A et al. (2002). Characterisation of MMCs by thermophysical measurements $16^{\text {th }}$ National Heat and Mass Transfer Conference $\& 5^{\text {th }}$ Indian Society for Heat and Mass Transfer/American Society of Mechanical Engineers Heat and Mass Transfer Conference, Calcutta, India, January, 216-222.

7. Karthikeyan B, Ramanathan S et al. (2010). Specific heat capacity measurement of $\mathrm{Al} / \mathrm{SiCp}$ composites by differential scanning calorimeter, Advanced Materials Research, vols 264-265, 669-674.

8. Basak D, Overfelt R A et al. (2003). Measurement of specific heat capacity and electrical resistivity of industrial alloys using pulse heating techniques, International Journal of Thermophys, vol 24(6), 1721-1733.

9. Kaschnitz E, Reiter P et al. (2002). Thermal expansion of liquid Ti-6Al-4V measured by electrostatic levitation, International Journal of Thermophysics, vol 23, 267.

10. Basak D, Boetinger W J et al. (1999). Effect of heating rate and grain size on the melting behavior of the alloy $\mathrm{Nb}-47$ mass\% $\mathrm{Ti}$ in pulse-heating experiments, Acta Materialia vol 47(11), 3147-3158.

11. Basak D, Kattner U R et al. (2000). Application of laser polarimetry to the measurement of specific heat capacity and enthalpy of the alloy $53 \mathrm{nb}-47 \mathrm{ti}$ (mass\%) in the temperature range 1600 to $2000 \mathrm{k}$ by a millisecond-resolution pulse heating technique, International Journal of Thermophysics vol 21(4), 913-926.

12. Brooks C R (1982). Heat treatment, structure and properties of nonferrous alloys, American Society of Metals, Metals Park, Ohio, 361.

13. Cezairliyan A, Phillips L C et al. (1995). Annual Report: NIST Consortium on casting of aerospace alloys 95. 